\title{
Predation pressure on bacteria increases along aquatic productivity gradients
}

\author{
Johanna Thelaus ${ }^{1,2, *}$, Pia Haecky ${ }^{3,5}$, Mats Forsman' ${ }^{2}$, Agneta Andersson ${ }^{1,4}$ \\ ${ }^{1}$ Department of Ecology and Environmental Science, Umeå University, 90187 Umeå, Sweden \\ ${ }^{2}$ CBRN Defence and Security, Swedish Defence Research Agency, 90182 Umeå, Sweden \\ ${ }^{3}$ Botanical Institute, University of Copenhagen, Oster Farimagsgade 2D, 1353 Copenhagen K, Denmark \\ ${ }^{4}$ Umeå Marine Sciences Centre, 91020 Hörnefors, Sweden \\ ${ }^{5}$ Present address: Bioras, Munkegårdsvej 6B, 3490 Kvistgård, Denmark
}

\begin{abstract}
To elucidate how predation pressure on bacteria is affected by increasing productivity in aquatic systems, we ran model simulations of a microbial food web. In addition, we conducted a meta-analysis of data from studies in seas and lakes. The model was run as a flow-through system simulating conditions ranging from oligotrophic to hypertrophic. The organisms included in the model were heterotrophic bacteria, phytoplankton, 3 size classes of protozoa and metazooplankton. Predation pressure was defined as flagellate and ciliate grazing per bacterial biomass. The food-web model simulations showed increasing predation pressure on bacteria with increasing productivity (estimated chlorophyll a concentration 0.2 to $112 \mu \mathrm{g} \mathrm{l}^{-1}$ ). This was explained by an increase in bacterial production and the ratio of protozoan to bacterial biomass with increasing productivity. The results of the model simulation were supported by the meta-analysis, which showed increasing protozoan predation pressure on bacteria with increasing productivity in aquatic systems (chlorophyll a concentration 0.1 to $250 \mu \mathrm{g} \mathrm{l}^{-1}$ ). The ratio of protozoan to bacterial biomass also increased with productivity in the meta-analysis of field data. Our results suggest that protozoa control the bacterial community by predation in high-productivity environments.
\end{abstract}

KEY WORDS: Bacteria $\cdot$ Protozoa $\cdot$ Predation $\cdot$ Microbial food web $\cdot$ Productivity $\cdot$ Regulation $\cdot$ Model $\cdot$ Omnivory

Resale or republication not permitted without written consent of the publisher

\section{INTRODUCTION}

Resource availability and predation are key factors affecting community structure and regulation of productivity in microbial food webs. It has been suggested that the availability of resources, or 'bottom-up' control of bacteria, dominates in low-productivity aquatic systems (Sommaruga 1995) and that the impact of predation (and viral lysis), or 'top-down' control of bacteria, dominates in high-productivity systems (Sanders et al. 1992). These suggestions are supported by the observation that the ratio of protozoan to bacterial biomass increases from nutrient-poor to nutrient-rich waters (Auer et al. 2004). However, these observations provide only indirect evidence since protozoa may use alternative food sources such as small phytoplankton. Recently, an alternative hypothesis regarding the relationship between the nutrient status of aquatic systems and the relative importance of resource and predation control of heterotrophic bacteria was proposed (Gasol et al. 2002a): that predation control of bacteria is stronger in low- than in high-productivity waters, and that resource control of bacteria dominates in high-productivity environments. This may occur due to cascade effects in the microbial food web. Effective control of heterotrophic nanoflagellates by ciliates in eutrophic systems might release bacteria from predation pressure, leading to bottom-up control of the bacterial community.

An immediate effect of increased nutrient load in aquatic systems is increased growth of the basal re- 
sources in the food web, i.e. phytoplankton and heterotrophic bacteria (Cole et al. 1988). Increases in basal productivity cascade up through the food web via the predator-prey chain, possibly resulting in increased predation on bacteria and phytoplankton. If the food web is linear and prey organisms do not develop predation defense mechanisms, the top predator would exhibit an increase in biomass with increasing productivity, while lower trophic levels might exhibit alternating responses in biomass levels (according to the exploitation ecosystem hypothesis) (Oksanen et al. 1981, Thingstad \& Sakshaug 1990). Thus, mechanisms controlling the structure of the microbial food web would shift between predation and resource control at different trophic levels. However, several mechanisms are known to modify this simple pattern: omnivory is common in aquatic food webs, increasing the complexity of trophic interactions (Diehl 2003). Introducing heterogeneity of trophic levels alters the response to increasing productivity compared to the predictions made by the exploitation ecosystem hypothesis (Leibold 1989, Abrams 1993). Furthermore, predation defense mechanisms are common in phytoplankton and bacterial communities in nutrient-rich waters, possibly as a response to increased predation pressure (Jürgens \& Güde 1994, Rousseau et al. 2000). In a microcosm study, Hall et al. (2006) showed that an inedible producer influenced the degree of top-down versus bottom-up regulation of a 2-level community. These observations suggest that if increased nutrient availability leads to increased predation and the development of general predation defenses in the lowest trophic levels, then bottom-up or resource control is likely to occur in nutrient-rich systems. This would lead to reduced efficiency of energy transfer within the food web. Taken together, top-down and bottom-up regulation should be considered as balancing processes regulating communities depending on the environment (Bell 2002).

The aim of the present study was to determine whether predation pressure on heterotrophic bacteria is affected by the nutrient status of the aquatic ecosystem. Predation pressure on bacteria was defined as total predation per bacterial biomass. The main hypothesis was that the predation pressure on bacteria increases with increasing productivity of the system. A possible alternative was that predation pressure decreases with productivity as a result of cascade effects and effective control of major bacterivores or as a result of the development of general predation defense mechanisms within the bacterial community. Our strategy was to combine model simulations with a meta-analysis of field data relating to productivity gradients. We used an ecosystem model based on flows of carbon, nitrogen and phosphorus within a size-structured microbial food web. Five trophic levels, ranging from bacteria-algae to metazooplankton, were included. Nutrient uptake was based on diffusion limitation, photosynthesis rates were based on light assimilation and predation was based on clearance rates. Available literature data on protozoan predation on bacteria in different aquatic systems was used in the meta-analysis.

\section{MATERIALS AND METHODS}

Model structure. A size-structured food web model, comprising 5 trophic levels, was used in the simulation experiment (Fig. 1) (food web model available from www.bioras.com/). The food web was based on generic organisms representing bacteria, phytoplankton, protozoa and metazooplankton (Fig. 1, Tables 1 \& 2). When designing the food-web model we aimed for simplicity; therefore the model was based mainly on physical constraints. Only a few empirical parameters were used. The organisms were defined by their cell radius, carbon density and $\mathrm{C}: \mathrm{N}$ and $\mathrm{C}: \mathrm{P}$ ratios. The processes driving the model were primary production $(\mathrm{PP})$, osmotrophy $\left(J_{\mathrm{d}}\right)$, respiration, resting metabolism $\left(\mathrm{C}_{\mathrm{Met}}\right)$ and predation (Pred). We ensured the general applicability of the

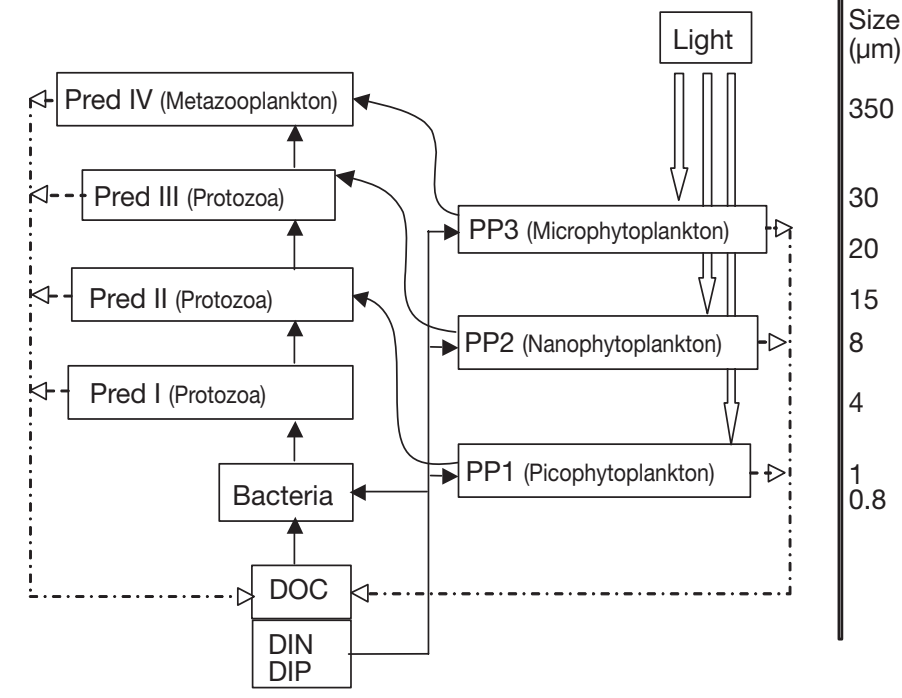

Fig. 1. Schematic view of the food web used in the simulations. Primary producers (PP) used light and inorganic nutrients (dissolved inorganic nitrogen [DIN], dissolved inorganic phosphate [DIP]) for growth. Bacteria consumed dissolved organic carbon (DOC), excreted by PPs or predators (Pred) and assimilated inorganic nutrients. Bacteria and primary producers were grazed by heterotrophic flagellates, ciliates or metazooplankton. Predators also grazed other predators 1 size class below them. Organisms are arranged according to cell size, which is indicated along the arrow to the right. Uptake, grazing or consumption (solid lines); excretion (dot-dash lines) 
Table 1. Model parameters for heterotrophic organisms. Met $t_{\mathrm{R}}$ resting metabolism, fraction of cell biomass respired per unit time; $\mu_{\max }$ : maximal specific bacterial growth rate; - : not constrained

\begin{tabular}{|c|c|c|c|c|c|c|c|c|c|c|c|}
\hline & & $\begin{array}{c}\text { Radius } \\
\text { ( } \mu \mathrm{m})\end{array}$ & 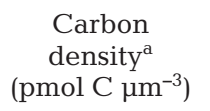 & $C: N^{b}$ & $\mathrm{C}: \mathrm{P}^{\mathrm{b}}$ & $\begin{array}{c}\operatorname{Met}_{\mathrm{R}}^{\mathrm{c}} \\
\left(\mathrm{h}^{-1}\right)\end{array}$ & 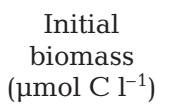 & $\begin{array}{c}\mu_{\max }^{d} \\
\left(h^{-1}\right)\end{array}$ & $\begin{array}{l}\text { Respira- } \\
\text { tion }^{\mathrm{e}, \mathrm{f}} \\
(\%)\end{array}$ & $\begin{array}{l}\text { Clearance } \\
\text { rate }^{g} \\
\left(\mathrm{~h}^{-1}\right)\end{array}$ & $\begin{array}{l}\text { Sloppy } \\
\text { feeding }^{\mathrm{h}} \\
(\%)\end{array}$ \\
\hline Bacteria & Bact & 0.3 & 0.01 & 10 & 100 & 0.001 & 3.4 & 0.25 & 60 & - & - \\
\hline \multicolumn{12}{|l|}{ Protozoa } \\
\hline Small & Pred I & 2 & 0.01 & 16 & 106 & 0.001 & 0.56 & - & 40 & $1 \times 10^{5}$ & 20 \\
\hline Medium & Pred II & 7.5 & 0.01 & 16 & 106 & 0.001 & 0.28 & - & 40 & $1 \times 10^{5}$ & 20 \\
\hline Large & Pred III & 15 & 0.01 & 16 & 106 & 0.001 & 0.066 & - & 40 & $1 \times 10^{5}$ & 20 \\
\hline $\begin{array}{l}\text { Metazoo- } \\
\text { plankton }\end{array}$ & Pred IV & 175 & 0.01 & 16 & 106 & 0.001 & 0.015 & - & 40 & $1 \times 10^{4}$ & 20 \\
\hline
\end{tabular}

Table 2. Model parameters for phytoplankton. Met $_{\mathrm{R}}$ : resting metabolism, fraction of cell biomass respired per unit time; $\mu_{\text {max }}$ : maximal specific bacterial growth rate

\begin{tabular}{|c|c|c|c|c|c|c|c|c|}
\hline & & $\begin{array}{c}\text { Cell radius } \\
(\mu \mathrm{m})\end{array}$ & $\begin{array}{l}\text { Carbon density }{ }^{\mathrm{a}} \\
\left(\mathrm{pmol} \mathrm{C} \mu \mathrm{m}^{-3}\right)\end{array}$ & $\mathrm{C}: \mathrm{N}^{\mathrm{b}}$ & $\mathrm{C}: \mathrm{P}^{\mathrm{b}}$ & $\begin{array}{l}\operatorname{Met}_{R}{ }^{c} \\
\left(h^{-1}\right)\end{array}$ & 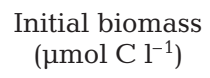 & $\begin{array}{r}\mu_{\max }{ }^{\mathrm{c}} \\
\left(\mathrm{h}^{-1}\right)\end{array}$ \\
\hline Picophytoplankton & PP1 & 0.5 & 0.01 & 10 & 100 & 0.001 & 1.3 & 0.02 \\
\hline Nanophytoplankton & PP2 & 2 & 0.01 & 16 & 106 & 0.001 & 1.3 & 0.02 \\
\hline Microphytoplankton & PP3 & 7.5 & 0.01 & 16 & 106 & 0.001 & 1.3 & 0.02 \\
\hline
\end{tabular}

model by careful design and selection of parameters. The ecosystem model was implemented in a System Dynamics environment as described by Blackburn et al. (1997). The ecosystem model was designed as a population dynamic model in a homogeneous volume of water, without spatial resolution. Therefore no random movement of organisms was incorporated.

Phytoplankton PP was calculated on the basis of light absorption. Assuming non-limiting inorganic carbon conditions, organic carbon production by algae was defined as:

$$
\mathrm{PP}=\Phi \pi r^{2} I
$$

where PP ( $\mu \mathrm{mol} \mathrm{C} \mathrm{h}^{-1}$ ) was the amount of organic carbon produced from the light $I$ ( $\mu$ mol quanta $\mathrm{cm}^{-2} \mathrm{~h}^{-1}$ ) reaching the light-exposed surface of the cell (area $\left[\mathrm{cm}^{2}\right]=\pi r^{2}$ ), and $\Phi$ the quantum yield of photosynthesis (mol C mol quanta ${ }^{-1}$ ). Phytoplankton maximal photosynthetic quantum yield $\left(\Phi_{\max }\right)$ was set to $0.013 \mathrm{~mol} \mathrm{C}$ mol quanta ${ }^{-1}$ (Sakshaug et al. 1991b). The rate of phytoplankton and bacterial nutrient uptake via osmotrophy was defined by the molecular diffusion of the substrate:

$$
J_{\mathrm{d}}=4 \pi \mathrm{rDC}
$$

where $J_{\mathrm{d}}\left(\mu \mathrm{mol} \mathrm{h} \mathrm{h}^{-1}\right)$ was the diffusive flux of the substrate, $r(\mathrm{~cm})$ the radius of the organism and $\mathrm{D}$ the diffusion constant. D was $3.6 \times 10^{-2} \mathrm{~cm}^{2} \mathrm{~h}^{-1}$ for inorganic nitrogen and phosphate and dissolved organic carbon
(DOC) (Jumars et al. 1993). $C\left(\mu \mathrm{mol} \mathrm{cm}{ }^{-3}\right)$ was the concentration of the substrate. Inorganic nutrients were required for growth of primary producers and bacteria, and DOC was required for bacterial growth. Uptake of inorganic nutrients and carbon was always based on the atomic ratio of the organisms (Tables $1 \& 2$ ). The nutrient-limited PP ( $\left.\mathrm{PP}_{\text {nutrient lim }}\right)$ was calculated on the basis of PP and phytoplankton nutrient uptake. The most limiting of the factors defined the $\mathrm{PP}_{\text {nutrient lim: }}$ :

$$
\mathrm{PP}_{\text {nutrient lim }}=\operatorname{Min}\left(J_{\mathrm{d}} \mathrm{C}: \mathrm{P}, J_{\mathrm{d}} \mathrm{C}: \mathrm{N}, \mathrm{PP}\right)
$$

The net $\mathrm{PP}$ by phytoplankton $\left(\mathrm{PP}_{\text {net }}\right)$ represents the $\mathrm{CO}_{2}$ assimilation rate and was calculated on the basis of the lowest of PP and PP nutrient lim. Exudation of DOC by phytoplankton was defined as $\mathrm{PP}$ minus $\mathrm{PP}_{\text {nutrient lim. }}$. Thus, the model simulated an ideal situation, where organic carbon exudates were only produced during nutrient limitation (Myklestad 1995). Maximum bacterial production $\left(\mathrm{BP}_{\max }, \mu \mathrm{mol} \mathrm{C} \mathrm{l}^{-1} \mathrm{~h}^{-1}\right)$ was calculated from the maximal specific bacterial growth rate $\left(\mu_{\max }=\right.$ $0.25 \mathrm{~h}^{-1}$ ) (Kemp et al. 1993) and the bacterial biomass

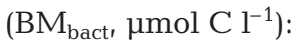

$$
\mathrm{BP}_{\max }=\mu_{\max } \mathrm{BM}_{\mathrm{bact}}
$$

Nutrient-limited BP (BP nutrient lim, $_{1}$ mol C $\left.\mathrm{l}^{-1} \mathrm{~h}^{-1}\right)$ was calculated on the basis of the most limiting nutrient, bacterial biomass and substrate diffusion. The most limiting nutrient (organic $\mathrm{C}, \mathrm{N}$ or $\mathrm{P}$ ) was determined by calculating the ratios between bacteria and growth 
medium $\mathrm{C}: \mathrm{P}$ and $\mathrm{C}: \mathrm{N}$. The lowest ratio of the two was used to calculate the gross production from the potential production:

$$
\mathrm{BP}_{\text {nutrient lim }}=\operatorname{Min}\left(J_{\mathrm{d}} \mathrm{C}: \mathrm{P}_{\text {Bact }}, J_{\mathrm{d}} \mathrm{C}: \mathrm{N}_{\text {Bact }}\right)
$$

The gross BP was corrected for respiration (60\%) (Zweifel et al. 1993). The particulate, organic and inorganic nutrient pools were updated accordingly.

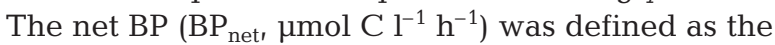
lower of either $\mathrm{BP}_{\text {nutrient lim }}$ or $\mathrm{BP}_{\text {max }}$. Resting carbon

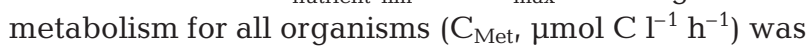
defined as biomass respired per unit time:

$$
\mathrm{C}_{\mathrm{Met}}=\mathrm{Met}_{\mathrm{R}} \mathrm{BM}
$$

where the resting metabolism $\left(\mathrm{Met}_{\mathrm{R}}, \mathrm{h}^{-1}\right)$ was set as being equivalent to mitochondrial respiration or dark respiration for primary producers (Tables 1 \& 2) (Sakshaug et al. 1991a) and BM was the organism carbon biomass ( $\mu \mathrm{mol} \mathrm{C}^{-1}$ ). The biomass of each organism group was integrated over time (Eq. 7), and depended on growth rate, respiration, grazing and photosynthesis for the primary producers. Mass was conserved in the model reactions, except in processes such as PP, where mass was added. The simulator integrated values in steps of $\Delta \mathrm{t}$ (corresponding to $0.005 \mathrm{~h}$ ).

$$
\mathrm{BM}(t+\Delta t)=\mathrm{BM}(t)+\frac{\mathrm{dBM}}{\mathrm{d} t} \Delta t
$$

Protozoan and metazoan predation (Pred, $\mu \mathrm{mol} \mathrm{C} \mathrm{l}^{-1}$ $\mathrm{h}^{-1}$ ) were defined in terms of volume-specific clearance rates $\left(\mathrm{Cl}_{\mathrm{vol}}=10^{5}\right.$ and $10^{4} \mathrm{~h}^{-1}$, respectively) (Fenchel 1987, Hansen et al. 1997) and the biomass of

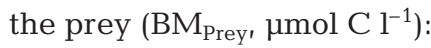

$$
\text { Pred }=\mathrm{Cl}_{\mathrm{vol}} \mathrm{BM}_{\text {Prey }}
$$

Each predator grazed on 1 size group below its own size (Fig. 1). During protozoan and metazoan grazing, $40 \%$ of the ingested cell material was lost to respiration and $20 \%$ as a result of sloppy feeding (Fig. 1) (Straile 1997, Strom et al. 1997).

Model simulation. Nineteen simulations were performed, simulating conditions from ultraoligotrophic to hypertrophic. The model was designed as a flowthrough system with a daily water exchange of $10 \%$. Eutrophication was caused by loading of dissolved inorganic nitrogen (DIN) and dissolved inorganic phosphorous (DIP) at a constant ratio $(\mathrm{N}: \mathrm{P}=39)$. DIN enrichment varied between $1.04 \times 10^{-3}$ and $6.25 \mu \mathrm{mol} \mathrm{l}^{-1}$ $\mathrm{h}^{-1}$, and DIP enrichment between $2.69 \times 10^{-5}$ and $0.161 \mu \mathrm{mol} \mathrm{l}^{-1} \mathrm{~h}^{-1}$. The daytime photosynthetically active radiation was $100 \mu \mathrm{mol}$ quanta $\mathrm{m}^{-2} \mathrm{~s}^{-1}$, which is a normal average light level in the photic zone and in the linear part of the light-response curve (Andersson et al. 1994). In the simulations, these light conditions were present for $12 \mathrm{~h} \mathrm{~d}^{-1}$. In all simulations the growth rates of protozoan predators (Pred I, II and III) and metazooplankton
(Pred IV) were below their maximum (i.e. $<1.55$ and $<0.06 \mathrm{~d}^{-1}$ for protozoa and metazooplankton, respectively). The simulations were run consecutively from ultraoligotrophic to hypertrophic conditions, and each simulation was initiated with the end values of the previous simulation. All simulations were run for $365 \mathrm{~d}$, at which point all simulations appeared stable (see Fig. 2). Average values and SDs for the last $30 \mathrm{~d}$ of the simulation runs were calculated for different response variables, e.g. biomasses, production and predation. Estimated chl a concentrations were used as a descriptor for system productivity, and were calculated from phytoplankton carbon biomass (Wienke \& Cloern 1987):

$$
\begin{aligned}
& \text { Estimated chl a }\left(\mu \mathrm{g}^{-1}\right)=0.02 \times \\
& \text { phytoplankton biomass }\left(\mu \mathrm{C}^{-1}\right)
\end{aligned}
$$

Protozoan predation pressure on bacteria $\left(\mathrm{PPrP}_{\text {bact }}\right.$ $\mathrm{h}^{-1}$ ) was defined as the ratio between predation on

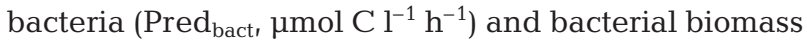

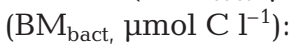

$$
\operatorname{PPrP}_{\text {bact }}=\operatorname{Pred}_{\text {bact }} / \mathrm{BM}_{\text {bact }}
$$

Compilation of field data. In order to evaluate the model output and the relationship between aquatic productivity and predation pressure on bacteria, we searched the recent literature for data on bacterial biomass, production and protozoan predation along with data on chlorophyll a (chl a) (Table 3). Chl a was used as an indicator of aquatic productivity since it is widely used and reported in most field studies. Fifteen marine and freshwater studies, which included all the required response variables and chl a values $>0.1 \mu \mathrm{g}$ $\mathrm{l}^{-1}$, were included in the analysis. Data from the phototrophic layer and the productive season were used. Most studies contained more than 1 measurement, and all data points (a total of 55) were included in the metaanalysis. In the papers considered, bacterial and protozoan abundances were determined using fluorescent staining methods and epifluorescence microscopy. When necessary, bacterial abundance was converted to biomass ( $\mu \mathrm{g} \mathrm{C} \mathrm{l}^{-1} \mathrm{~h}^{-1}$ ), assuming $20 \mathrm{fg} \mathrm{C} \mathrm{cell}^{-1}$ (Lee \& Fuhrman 1987). In a few cases protozoan biomass was calculated from abundances, using fixed biovolumes

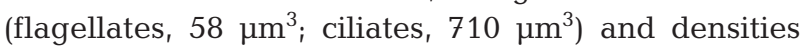

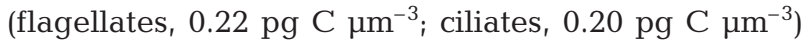
(Table 4) (Wieltschnig et al. 1999, 2003). BP was generally measured using the ${ }^{3} \mathrm{H}$-thymidine technique (76\% of the data), but in some studies ${ }^{3} \mathrm{H}$-leucine and ${ }^{14} \mathrm{C}$-leucine were used (Table 4 ). For $55 \%$ of the data, protozoan predation was measured using fluorescently labeled bacteria (FLB). In other cases fluorescently labeled microbeads (FLM) and radio-labeled bacteria (RLB) were used (Table 4). When only daily values for protozoan predation and BP were available, hourly rates were calculated by dividing the data by 24 . 


\begin{tabular}{|c|c|c|c|c|c|c|c|c|c|c|c|c|c|c|c|}
\hline 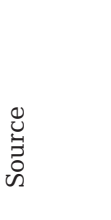 & 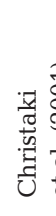 & & $\begin{array}{l}\vec{\sigma} \\
\overrightarrow{0} \\
\widetilde{\Xi} \\
\Xi\end{array}$ & $\underset{\sigma}{\infty}$ & & & $\frac{\pi}{\tilde{d}}$ & $\begin{array}{l}\frac{\pi}{0} \\
\frac{0}{0}\end{array}$ & 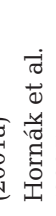 & $\begin{array}{l}\frac{\pi}{\sigma} \\
\stackrel{\omega}{\omega}\end{array}$ & 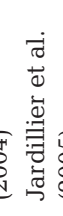 & & $\begin{array}{r}\overrightarrow{0} \\
-\overrightarrow{0}\end{array}$ & $\frac{\pi}{\pi}$ & 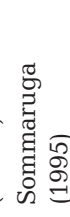 \\
\hline 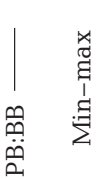 & \begin{tabular}{l}
\multirow{H}{*}{} \\
0 \\
0 \\
1 \\
$\vdots$ \\
0 \\
0 \\
0
\end{tabular} & $\begin{array}{l}\text { oे } \\
0 \\
0 \\
1 \\
1 \\
0 \\
0 \\
0\end{array}$ & $\begin{array}{l}\overrightarrow{\tilde{o}} \\
0 \\
\dot{1} \\
0 \\
0 \\
0 \\
0\end{array}$ & $\begin{array}{l}0 \\
0 \\
0 \\
0 \\
1 \\
0 \\
0 \\
0 \\
0\end{array}$ & $\begin{array}{l}\text { N. } \\
0 \\
0 \\
1 \\
1 \\
0 \\
0 \\
0\end{array}$ & $\overparen{\pi}$ & 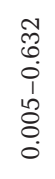 & g & $\widetilde{Z}$ & $\stackrel{\pi}{\pi}$ & $\begin{array}{l}0 \\
8 \\
0 \\
1 \\
1 \\
0 \\
0 \\
0\end{array}$ & $\pi$ & 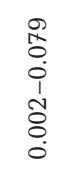 & $\mathbb{g}$ & $\begin{array}{l}\stackrel{m}{N} \\
0 \\
1 \\
1 \\
0 \\
0 \\
0 \\
0\end{array}$ \\
\hline$\stackrel{8}{8}$ & $\stackrel{\infty}{\circ}$ & 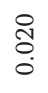 & $\begin{array}{l}\text { Oे } \\
\text { ¿. }\end{array}$ & 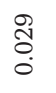 & $\stackrel{m}{\stackrel{m}{0}}$ & శ & 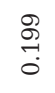 & $\begin{array}{l}\text { a. } \\
\stackrel{8}{0} \\
0\end{array}$ & $\begin{array}{l}\mathscr{g} \\
\stackrel{0}{0}\end{array}$ & T & \%̊̊. & $\begin{array}{l}\stackrel{8}{0} \\
\text { đ్ }\end{array}$ & 范 & $\underset{\mathscr{a}}{\tilde{a}}$ & $\begin{array}{l}\text { ஜ̊ } \\
\stackrel{0}{0}\end{array}$ \\
\hline 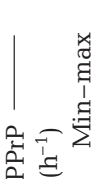 & 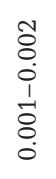 & \begin{tabular}{l}
7 \\
\multirow{1}{1}{} \\
0 \\
1 \\
1 \\
0 \\
0 \\
0
\end{tabular} & $\begin{array}{l}\overrightarrow{1} \\
0 \\
0 \\
1 \\
\tilde{o} \\
0 \\
0\end{array}$ & $\begin{array}{l}0 \\
0 \\
0 \\
0 \\
1 \\
0 \\
0 \\
0 \\
0\end{array}$ & $\begin{array}{l}\infty \\
0 \\
0 \\
1 \\
0 \\
0 \\
0 \\
0\end{array}$ & $\begin{array}{l}m \\
0 \\
0 \\
1 \\
1 \\
\delta \\
0 \\
0\end{array}$ & $\begin{array}{l}ت \overrightarrow{0} \\
0 \\
0 \\
1 \\
\tilde{0} \\
0 \\
0 \\
0\end{array}$ & $\stackrel{\pi}{\pi}$ & 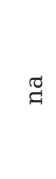 & $\begin{array}{l}+ \\
0 \\
0 \\
1 \\
1 \\
0 \\
0 \\
0\end{array}$ & $\begin{array}{l}8 \\
8 \\
0 \\
1 \\
0 \\
0 \\
0 \\
0\end{array}$ & $\tilde{q}$ & 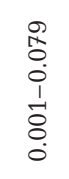 & $\begin{array}{l}\text { 今े } \\
\text { N̦} \\
0 \\
1 \\
0 \\
0 \\
0 \\
0\end{array}$ & 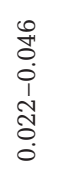 \\
\hline 8 & $\vec{\circ}$ & $\begin{array}{l}\text { 管 } \\
\text { O }\end{array}$ & $\begin{array}{l}0 \\
: \\
0\end{array}$ & $\begin{array}{l}\circ \\
\stackrel{\circ}{0}\end{array}$ & 啇 & $\begin{array}{l}\tilde{o} \\
\stackrel{0}{\circ}\end{array}$ & 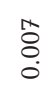 & $\begin{array}{l}\vec{H} \\
\stackrel{0}{0}\end{array}$ & $\begin{array}{l}\infty \\
\stackrel{0}{0} \\
0 \\
0\end{array}$ & $\begin{array}{l}\tilde{o} \\
\text { ○े }\end{array}$ & $\begin{array}{l}\text { âे } \\
\stackrel{8}{0}\end{array}$ & $\stackrel{\text { âे }}{0}$ & \begin{tabular}{l}
0 \\
\multirow{O}{0}{} \\
0 \\
0
\end{tabular} & $\begin{array}{l}\hat{n} \\
\stackrel{n}{n} \\
0\end{array}$ & $\begin{array}{l}\text { "r. } \\
\stackrel{0}{0} \\
0 \\
0\end{array}$ \\
\hline 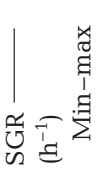 & $\begin{array}{l}0 \\
0 \\
0 \\
1 \\
\vdots \\
0 \\
0 \\
0\end{array}$ & $\begin{array}{l}\text { Ü } \\
0 \\
0 \\
1 \\
0 \\
0 \\
0 \\
0\end{array}$ & $\begin{array}{l}0 \\
0 \\
0 \\
1 \\
1 \\
0 \\
0 \\
0\end{array}$ & $\begin{array}{l}\text { तु } \\
0 \\
0 \\
1 \\
0 \\
0 \\
0 \\
0\end{array}$ & $\begin{array}{l}m \\
0 \\
0 \\
0 \\
1 \\
\infty \\
0 \\
0 \\
0\end{array}$ & $\begin{array}{l}\infty \\
0 \\
0 \\
1 \\
1 \\
0 \\
0 \\
0\end{array}$ & $\begin{array}{l}0 \\
0 \\
0 \\
0 \\
1 \\
0 \\
0 \\
0\end{array}$ & శ & $\stackrel{\pi}{\not}$ & $\begin{array}{l}\text { ते } \\
0 \\
0 \\
1 \\
\vdots \\
0 \\
0\end{array}$ & $\begin{array}{l}\overrightarrow{0} \\
0 \\
0 \\
\dot{0} \\
0 \\
0\end{array}$ & $\widetilde{\pi}$ & $\begin{array}{l}\infty \\
\tilde{O} \\
0 \\
1 \\
+ \\
0 \\
0 \\
0\end{array}$ & 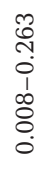 & $\begin{array}{l}0 \\
0 \\
0 \\
0 \\
1 \\
0 \\
0 \\
0 \\
0\end{array}$ \\
\hline & $\vec{\circ}$ & 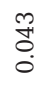 & 苂 & $\stackrel{m}{0}$ & $\begin{array}{l}\infty \\
\stackrel{0}{0}\end{array}$ & 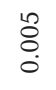 & $\begin{array}{l}m \\
\vdots \\
0\end{array}$ & $\begin{array}{l}\stackrel{8}{0} \\
\stackrel{0}{0}\end{array}$ & $\begin{array}{l}\text { I্ } \\
\stackrel{0}{0}\end{array}$ & $\stackrel{\vec{O}}{0}$ & $\vec{\delta}$ & $\overrightarrow{0}$ & $\begin{array}{l}\widetilde{O} \\
0 \\
0\end{array}$ & 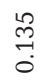 & $\begin{array}{l}\text { L } \\
\text { o. } \\
0\end{array}$ \\
\hline 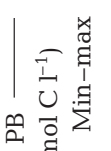 & $\begin{array}{l}n \\
0 \\
0 \\
1 \\
0 \\
0 \\
0\end{array}$ & $\begin{array}{l}\stackrel{H}{H} \\
\stackrel{1}{1} \\
\infty \\
\stackrel{\infty}{0}\end{array}$ & 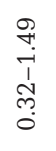 & $\begin{array}{l}\stackrel{0}{0} \\
\text { in } \\
i \\
8 \\
\dot{i}\end{array}$ & $\begin{array}{l}\infty \\
0 \\
i \\
1 \\
1 \\
0 \\
0\end{array}$ & $\tilde{g}$ & $\begin{array}{l}\infty \\
\infty \\
0 \\
0 \\
1 \\
\infty \\
\infty \\
0 \\
0\end{array}$ & $\tilde{g}$ & $\stackrel{\pi}{q}$ & $\widetilde{\pi}$ & $\begin{array}{l}n \\
0 \\
0 \\
1 \\
0 \\
0 \\
0\end{array}$ & $\stackrel{\pi}{q}$ & $\begin{array}{l}0 \\
0 \\
9 \\
\overrightarrow{1} \\
0 \\
\infty \\
-i\end{array}$ & $\underset{\widetilde{q}}{\sigma}$ & 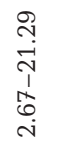 \\
\hline & $\begin{array}{l}0 \\
\stackrel{0}{0} \\
\dot{0}\end{array}$ & $\begin{array}{l}8 \\
0 \\
0\end{array}$ & 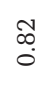 & $\stackrel{\widetilde{N}}{\overparen{\sim}}$ & $\stackrel{\overbrace{}}{\rightarrow}$ & $\stackrel{\pi}{q}$ & $\underset{\overparen{N}}{\stackrel{\sim}{N}}$ & $\begin{array}{l}\infty \\
\infty \\
\infty\end{array}$ & $\begin{array}{l}\tilde{R} \\
\text { Hु }\end{array}$ & $\stackrel{\pi}{q}$ & 号 & $\begin{array}{l}\stackrel{0}{\circ} \\
\stackrel{\sim}{\sim}\end{array}$ & $\underset{\ddot{\leftrightarrow}}{\ddot{\sim}}$ & $\stackrel{\pi}{a}$ & 管 \\
\hline 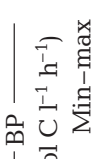 & 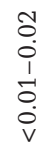 & 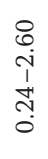 & $\begin{array}{l}\stackrel{0}{1} \\
0 \\
1 \\
\stackrel{1}{1} \\
0\end{array}$ & $\begin{array}{l}8 \\
\stackrel{1}{1} \\
0 \\
0 \\
0 \\
0\end{array}$ & 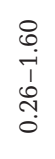 & $\begin{array}{l}n \\
n \\
0 \\
1 \\
\omega \\
0 \\
0\end{array}$ & $\begin{array}{l}8 \\
+ \\
1 \\
8 \\
0 \\
0\end{array}$ & $\widetilde{g}$ & $\widetilde{\pi}$ & 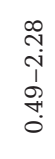 & $\begin{array}{l}7 \\
7 \\
1 \\
0 \\
0 \\
0\end{array}$ & $\widetilde{Z}$ & $\begin{array}{l}\infty \\
\infty \\
0 \\
0 \\
0 \\
1 \\
0 \\
0 \\
-i\end{array}$ & $\begin{array}{l}\text { No } \\
\infty \\
\stackrel{\leftrightarrow}{1} \\
0 \\
0 \\
0 \\
0\end{array}$ & $\begin{array}{l}8 \\
\dot{0} \\
\dot{m} \\
1 \\
8 \\
i \\
i\end{array}$ \\
\hline 具焉 & $\overrightarrow{0}$ & $\stackrel{\mathscr{P}}{\rightarrow}$ & $\stackrel{n}{2}$ & $\begin{array}{l}\infty \\
\infty \\
0\end{array}$ & $\begin{array}{l}\infty \\
\stackrel{\circ}{\circ} \\
0\end{array}$ & 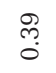 & $\stackrel{\overbrace{}}{\rightarrow}$ & î. & $\stackrel{N}{\sigma}$ & $\stackrel{\mathscr{L}}{\stackrel{\leftrightarrow}{-}}$ & $\stackrel{8}{8}$ & کू. & $\underset{\leftrightarrow}{\stackrel{P}{S}}$ & 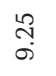 & $\stackrel{\circ}{\stackrel{0}{-}}$ \\
\hline 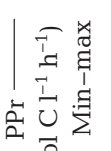 & 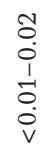 & $\begin{array}{l}0 \\
\stackrel{1}{0} \\
\dot{p} \\
1 \\
+! \\
0\end{array}$ & 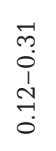 & 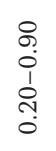 & \begin{tabular}{l}
$\mathfrak{7}$ \\
\multirow{1}{1}{} \\
0 \\
0 \\
0 \\
0
\end{tabular} & 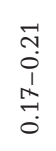 & 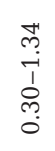 & $\stackrel{\pi}{\not}$ & $\widetilde{q}$ & $\begin{array}{l}\text { से } \\
0 \\
0 \\
0 \\
0 \\
0 \\
0\end{array}$ & $\begin{array}{l}0 \\
\stackrel{7}{1} \\
\dot{1} \\
0 \\
0 \\
0\end{array}$ & $\stackrel{\pi}{q}$ & $\begin{array}{l}\hat{n} \\
\dot{0} \\
\dot{0} \\
1 \\
0 \\
0 \\
-i\end{array}$ & 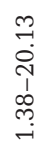 & 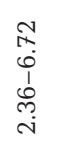 \\
\hline 恶交 & $\overrightarrow{0}$ & : & $\vec{N}$ & $\underset{0}{\sharp}$ & $\begin{array}{l}0 \\
\infty \\
0 \\
0\end{array}$ & $\stackrel{\leftrightarrow}{\circ}$ & $\begin{array}{l}\infty \\
\stackrel{\infty}{\dddot{0}} \\
0\end{array}$ & $\stackrel{\leftrightarrow}{\rightarrow}$ & $\underset{\infty}{\infty}$ & $\stackrel{N}{\text { N. }}$ & \& & $\stackrel{m}{\rightarrow}$ & $\underset{\sim}{\rightarrow}$ & \begin{tabular}{l}
0 \\
\multirow{2}{*}{} \\
$\stackrel{9}{0}$
\end{tabular} & $\overrightarrow{\stackrel{\infty}{+}}$ \\
\hline 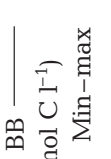 & $\begin{array}{l}\text { N. } \\
0 \\
\vdots \\
0 \\
0 \\
0\end{array}$ & $\begin{array}{l}\stackrel{0}{\dot{j}} \\
\underset{H}{1} \\
\vdots \\
\stackrel{i}{i}\end{array}$ & $\begin{array}{l}0 \\
0 \\
0 \\
0 \\
1 \\
0 \\
0 \\
0\end{array}$ & $\begin{array}{l}0 \\
0 \\
0 \\
0 \\
1 \\
\dot{j} \\
\dot{q}\end{array}$ & $\begin{array}{l}0 \\
\dot{0} \\
\stackrel{m}{7} \\
\vdots \\
\infty \\
\infty \\
\infty\end{array}$ & $\begin{array}{l}0 \\
i \\
0 \\
i \\
0 \\
\dot{0}\end{array}$ & $\begin{array}{l}0 \\
\dot{0} \\
0 \\
1 \\
0 \\
\dot{0} \\
\infty\end{array}$ & $\widetilde{q}$ & Z्व & $\begin{array}{l}0 \\
\dot{H} \\
\stackrel{+}{1} \\
0 \\
\dot{1} \\
\infty\end{array}$ & 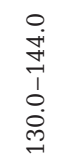 & $\mathscr{g}$ & $\begin{array}{l}0 \\
0 \\
0 \\
\stackrel{1}{1} \\
0 \\
\dot{8}\end{array}$ & $\begin{array}{l}0 \\
\dot{0} \\
\infty \\
1 \\
\infty \\
\mathbb{0}\end{array}$ & $\begin{array}{l}0 \\
\dot{0} \\
\stackrel{1}{1} \\
1 \\
\dot{0} \\
\infty\end{array}$ \\
\hline & $\vec{\infty}$ & 릴 & $\vec{i}$ & $\begin{array}{l}\text { m. } \\
\text { in }\end{array}$ & $\begin{array}{l}0 \\
\infty \\
\exists \\
\exists\end{array}$ & $\stackrel{0}{\infty}$ & $\stackrel{\circ}{\stackrel{i}{J}}$ & : & 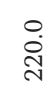 & $\begin{array}{l}\infty \\
\stackrel{\varrho}{\exists}\end{array}$ & 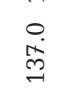 & $\stackrel{\circ}{\dot{0}}$ & $\begin{array}{l}\vec{H} \\
\vec{H} \\
\vec{m}\end{array}$ & $\underset{\phi}{\not}$ & مْ \\
\hline 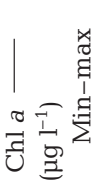 & $\begin{array}{l}0 \\
0 \\
0 \\
1 \\
0 \\
0 \\
0\end{array}$ & $\underset{-}{\stackrel{8}{-}}$ & $\underset{-}{\stackrel{8}{-}}$ & $\begin{array}{l}8 \\
i \\
i \\
\vdots \\
i \\
i \\
-i\end{array}$ & $\begin{array}{l}0 \\
i \\
i \\
1 \\
1 \\
\infty \\
0\end{array}$ & $\begin{array}{l}0 \\
\stackrel{1}{i} \\
i \\
\stackrel{1}{d} \\
0 \\
i \\
-i\end{array}$ & $\begin{array}{l}\text { ते } \\
1 \\
o \\
0 \\
0\end{array}$ & $\stackrel{\pi}{\pi}$ & $\widetilde{q}$ & $\begin{array}{l}8 \\
0 \\
9 \\
1 \\
1 \\
0 \\
-i\end{array}$ & $\begin{array}{l}0 \\
0 \\
\infty \\
1 \\
1 \\
8 \\
i\end{array}$ & I & 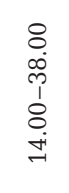 & 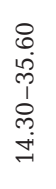 & 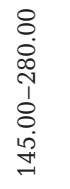 \\
\hline \multirow[t]{2}{*}{$\$$} & $\overrightarrow{\tilde{o}}$ & $\underset{ن}{\stackrel{\leftrightarrow}{\circ}}$ & $\underset{\sim}{\stackrel{\leftrightarrow}{-}}$ & $\stackrel{\infty}{\stackrel{\infty}{\sim}}$ & $\stackrel{\infty}{\stackrel{\infty}{+}}$ & $\stackrel{\leftrightarrow}{\leftrightarrow}$ & $\stackrel{\infty}{\vec{b}}$ & $\underset{\infty}{\stackrel{0}{0}}$ & in & $\begin{array}{l}\infty \\
\infty \\
\infty\end{array}$ & ڤ్ & : & $\begin{array}{l}\mathbb{H} \\
\underset{\sim}{\tilde{N}}\end{array}$ & 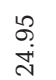 & $\begin{array}{l}0 \\
\stackrel{i}{1} \\
\text { di }\end{array}$ \\
\hline & in & 0 & $\sigma$ & 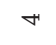 & 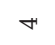 & $N$ & in & - & - & in & N & $\rightarrow$ & $a$ & N & $r$ \\
\hline
\end{tabular}


Table 4. Sources of data and methods used for the meta-analysis. FLB: fluorescent-labeled bacteria; BP-Bab: difference between bacterial production and observed bacterial abundance; RLB: radio-labeled bacteria; FLM: fluorescent-labeled microbeads; H3t: incorporation of $\mathrm{H}$-thymidine; C(14)l: incorporation of C-leucine; H31: incorporation of H-leucine; F: flagellates; P: flagellates and ciliates; S: spectrophotometry; F: fluorescence; na: not available

\begin{tabular}{|c|c|c|c|c|c|}
\hline $\begin{array}{l}\text { Protozoan } \\
\text { predation }\end{array}$ & $\begin{array}{l}\text { Bacterial } \\
\text { production }\end{array}$ & $\begin{array}{l}\text { Predator } \\
\text { biomass }\end{array}$ & Chl a & Environment & Source \\
\hline FLB & H31 & $\mathrm{F}$ & $\mathrm{F}$ & Mediterranean Sea & Christaki et al. (2001) \\
\hline RLB & $\mathrm{H} 3 \mathrm{t}$ & $\mathrm{F}$ & na & Adriatic Sea & Solic \& Krstulovic (1994) \\
\hline FLB & $\mathrm{H} 3 \mathrm{t}$ & $\mathrm{F}^{\mathrm{a}}$ & $\mathrm{S}$ & La Salvaje Beach, Spain & Barcina et al. (1992) \\
\hline FLB & $\mathrm{C}(14) 1$ & $\mathrm{P}$ & $\mathrm{S}$ & Piburger See, Austria & Sommaruga \& Psenner (1995) \\
\hline $\mathrm{BP}-\mathrm{Bab}$ & H3t & $\mathrm{F}$ & na & Gulf of Finland, Baltic Sea, Finland & Kuuppo-Leinikki (1990) \\
\hline Clearance rate & H3t & $\mathrm{F}^{\mathrm{a}}$ & $\mathrm{S}$ & Lake Pavin, France & Bettarel et al. (2003) \\
\hline FLM & H3t & $\mathrm{P}$ & $\mathrm{S}^{\mathrm{b}}$ & Lake Bourget, France & Comte et al. (2006) \\
\hline FLB & H3t & $\mathrm{P}$ & $\mathrm{S}$ & Sau Reservoir, Spain & Šimek et al. (2001a) \\
\hline FLB & H3t & $\mathrm{F}^{\mathrm{a}}$ & na & Rimov Reservoir, Czech Republic & Hornñák et al. (2005) \\
\hline Tracer particles & H3t & na & $\mathrm{S}$ & Lakes Pavin and Aydat, France & Bettarel et al. (2004) \\
\hline FLM & H3t & $\mathrm{P}^{\mathrm{a}}$ & $\mathrm{S}^{\mathrm{b}}$ & Sep Reservoir, France & Jardillier et al. (2005) \\
\hline FLB & H3t & $\mathrm{F}^{\mathrm{a}}$ & $\mathrm{S}$ & Rimov Reservoir, Czech Republic & Šimek et al. (2003) \\
\hline FLB & H3t & $\mathrm{P}^{\mathrm{a}}$ & $\mathrm{S}$ & Rimov Reservoir, Czech Republic & Šimek et al. (2001b) \\
\hline FLB & H3t & $\mathrm{P}^{\mathrm{a}}$ & $\mathrm{S}$ & Sau Reservoir, Spain & Gasol et al. (2002b) \\
\hline FLB & $\mathrm{C}(14) 1$ & $\mathrm{P}$ & $\mathrm{S}$ & Lake Rodó, Uruguay & Sommaruga (1995) \\
\hline
\end{tabular}

Statistical analysis. Linear regression was used to analyze how the response variables could explain the predation pressure on bacteria in the model simulation and in the meta-analysis (SPSS 11 for Windows). All data were log-transformed prior to statistical analysis.

\section{RESULTS}

\section{Model simulations}

The average concentrations of total phosphorus in the simulations ranged from 0.07 to $394 \mu \mathrm{mol} \mathrm{P}^{-1}$, corresponding to ultra oligotrophic and hypertrophic conditions, respectively (Klapper 1991). Estimated chl a concentrations ranged from 0.2 to $112 \mu \mathrm{g} \mathrm{l}^{-1}$. Total P concentrations were strongly correlated with chl a concentrations (chl $a=0.283 \times$ total P $+0.141, \mathrm{r}^{2}=0.999$, $\mathrm{p}<0.01$ ). All simulations appeared stable at the end of the $365 \mathrm{~d}$ runs (Fig. 2). In the model simulation, the bacterial biomass increased 100-fold with increasing chl a concentration. However, over medium chl a concentrations $\left(\sim 3\right.$ to $\left.11 \mathrm{\mu g} \mathrm{l}^{-1}\right)$, corresponding to mesotrophic conditions (Klapper 1991), the bacterial biomass remained stable (Fig. 3, right-hand panels). BP and predation from predator I also increased with increasing system productivity. The specific growth rate of bacteria increased with productivity to medium

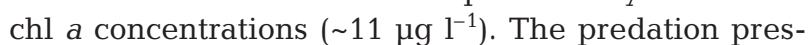
sure on bacteria, i.e. the predation per unit of bacterial biomass, increased from the lowest estimated chl a
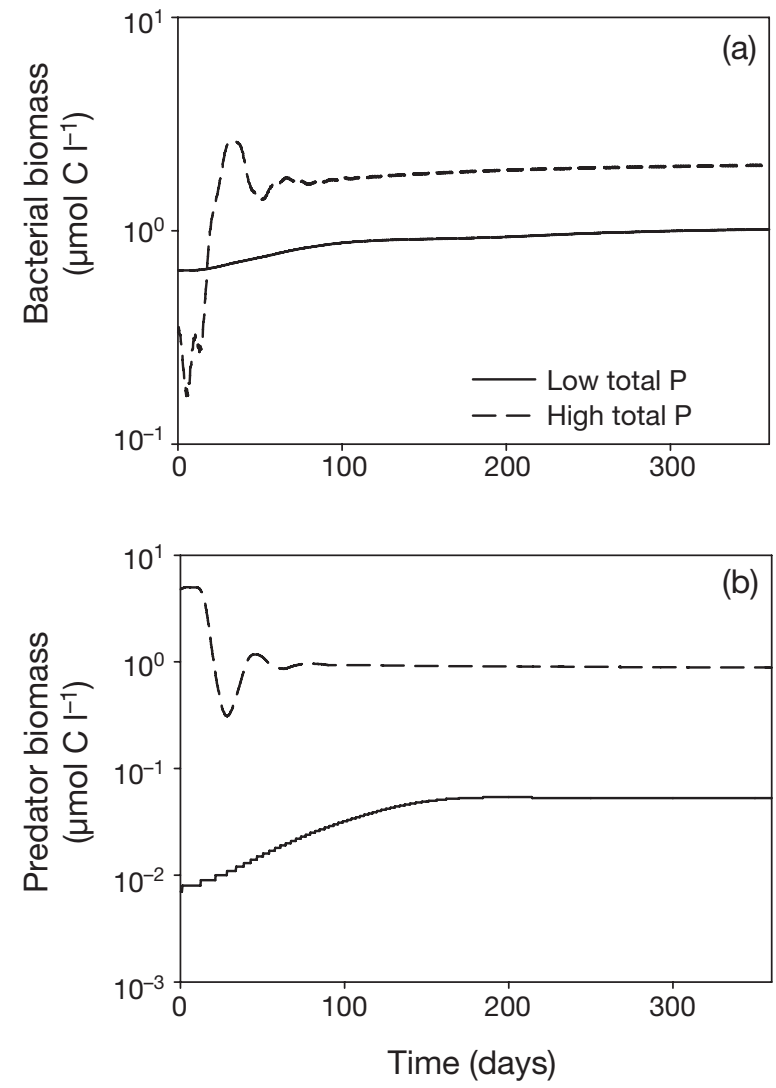

Fig. 2. Time series data on (a) bacterial biomasses and (b) biomass of predator I in the food-web model simulation at low (solid line) and high productivity (dashed line) (total P at 3.3 and $40.1 \mu \mathrm{mol} \mathrm{l}^{-1}$, respectively) 


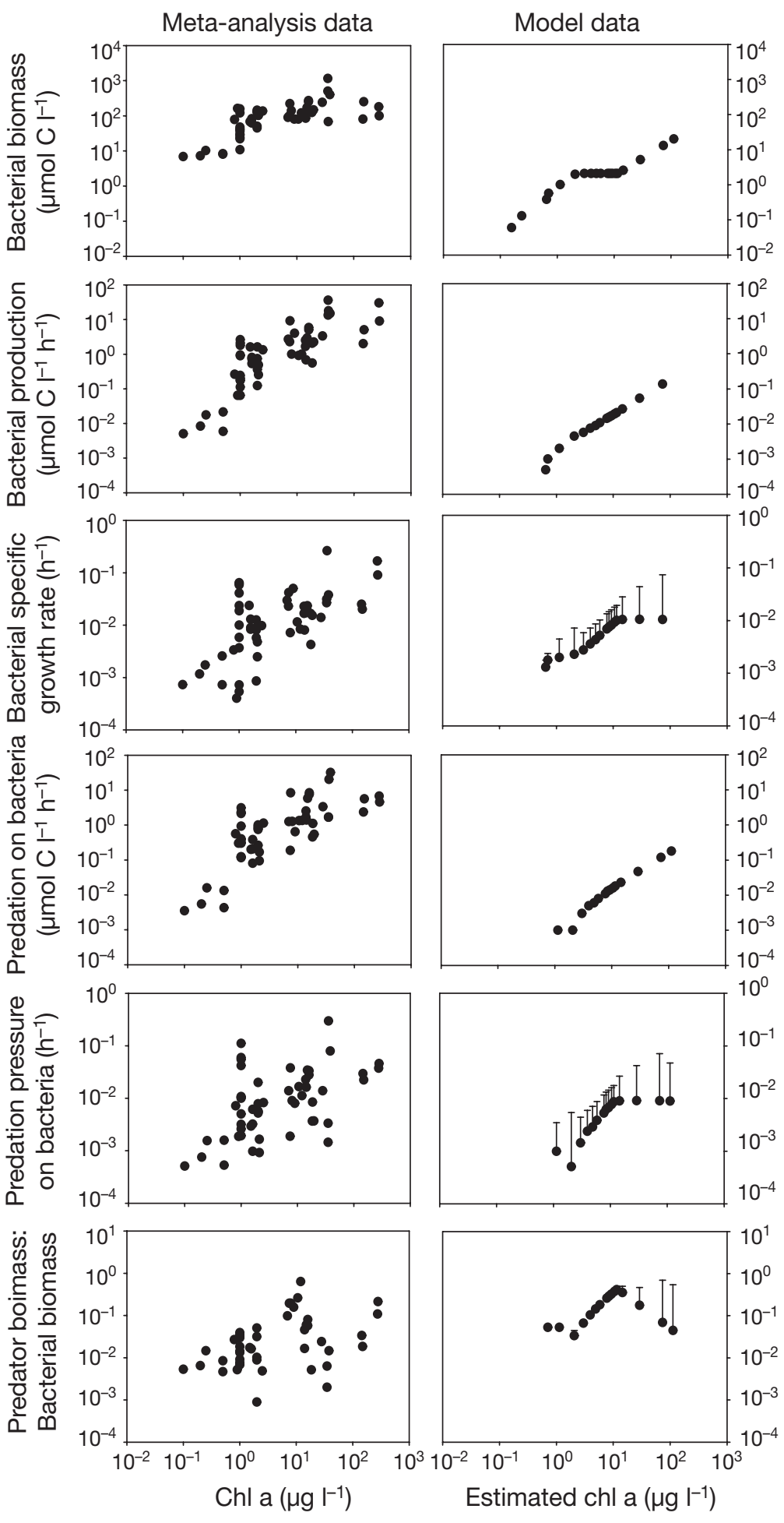

Fig. 3. Field and model data on bacterial biomass, bacterial production, bacterial production per unit biomass (specific growth rate), predation on bacteria, predation pressure on bacteria (predation per unit bacterial biomass) and predator to bacterial biomass ratio along aquatic productivity gradients, as indicated by chl a concentration (field data) and estimated chl a concentration from phytoplankton biomass (model data). Field data set includes marine and freshwater studies $(n=55)$. Model data are average values for the last $30 \mathrm{~d}$ of the simulations. Error bars indicate SD of means concentration to the medium concentrations $\left(\sim 11 \mu \mathrm{g} \mathrm{l}^{-1}\right)$ (Fig. 3, right-hand panels). The ratio of predators to bacterial biomass exhibited a hump-shaped pattern with a maximal ratio at medium chl a concentrations $\left(\sim 11 \mu \mathrm{g} \mathrm{l}^{-1}\right)$. Thus, increase in predation pressure along the nutrient gradient could mainly be explained by the increase in predator biomass and BP $\left(\mathrm{r}^{2}=\right.$ 0.998 and 0.896 for linear and hyperbole regression, respectively, $p<0.01$ ) (Fig. $4 \mathrm{c}, \mathrm{d}$ ). The biomass of small protozoa (protozoan predator I) increased over the same nutrient range, while the biomass of intermediate-sized protozoa (protozoan predator II) increased stepwise with increasing system productivity (Fig. 5). Biomass of predator III, i.e. large-sized protozoa, was relatively stable over the entire nutrient range. Further, the biomass of zooplankton (predator IV) increased over the nutrient range.

\section{Meta-analysis of field data}

The aquatic environments studied represented a large productivity range (Table 3, Fig. 3, left-hand panels), with chl a concentrations ranging from 0.1 to $280 \mathrm{\mu g} \mathrm{l}^{-1}$, corresponding to oligotrophic to hypertrophic conditions (Klapper 1991). Thus, the field study covered a wider productivity range than the model simulations. The meta-analysis showed that bacterial biomass increased 10-fold and BP 1000 -fold over the productivity range (Fig. 3, left-hand panels). Consequently, the specific growth rate of bacteria (or BP per unit of biomass) increased over the range. Protozoan predation on bacteria increased 1000-fold and predation pressure on bacteria (predation per unit of bacterial biomass) 100-fold over the productivity range. In accordance with these results, the ratio of protozoan to bacterial biomass increased over the range, indicating increasing importance of predation in structuring the bacterial community with increasing nutrient availability. The observed increase in predation pressure along the productivity gradient could mainly be explained by the increasing predator biomass and $\mathrm{BP}\left(\mathrm{r}^{2}=0.350\right.$ and 0.489, respectively, p < 0.01) (Fig. 4 a,b). 

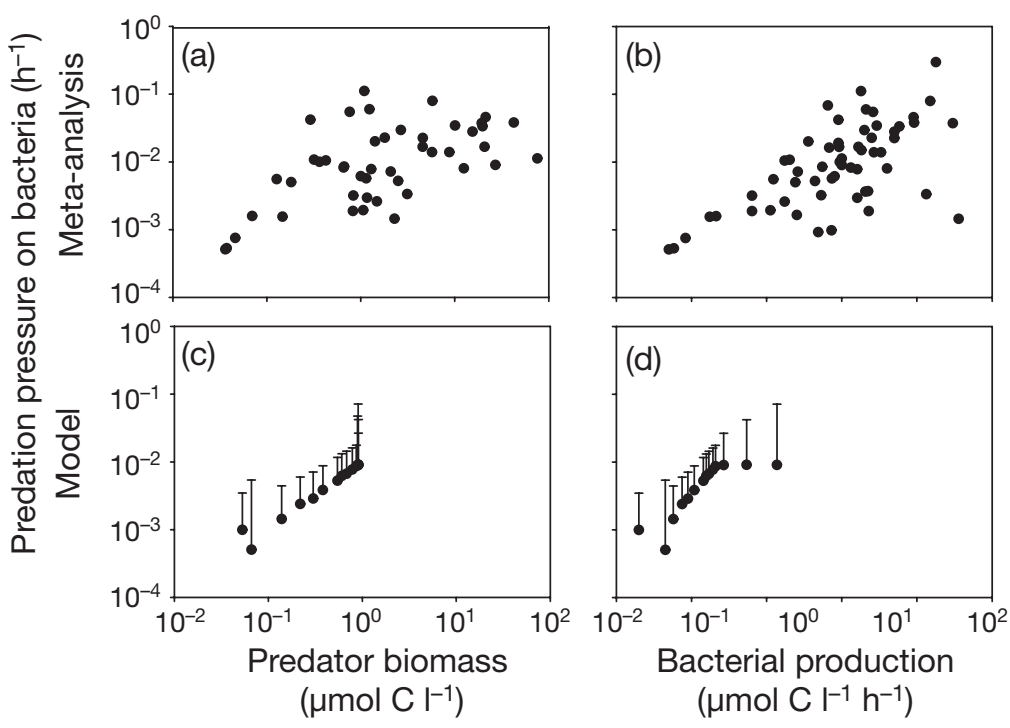

Fig. 4. Predation pressure on bacteria in response to protozoan biomass and bacterial production. Results from the $(\mathrm{a}, \mathrm{b})$ meta-analysis and $(\mathrm{c}, \mathrm{d})$ linear model simulation. Error bars indicate SDs of averages (last $30 \mathrm{~d}$ of the simulations)

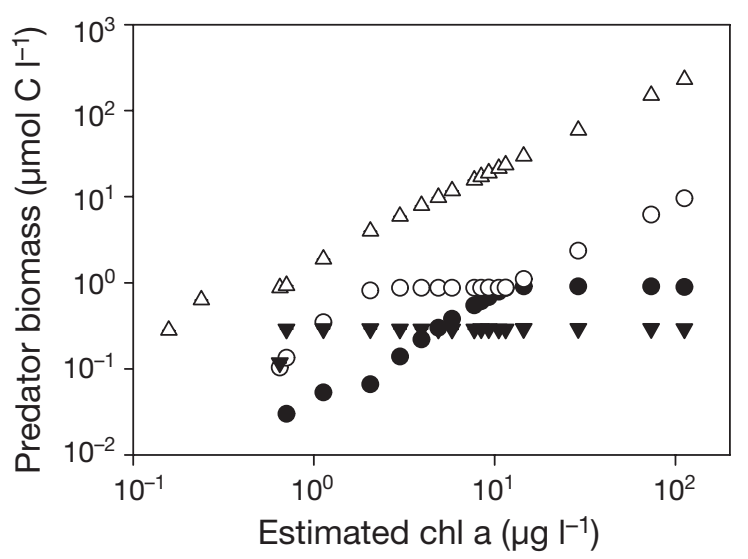

Fig. 5. Predator biomass in model simulations at increasing productivity, as indicated by estimated chl a concentration. Predators I (๑), II (O), III ( $\mathbf{\nabla})$ and IV $(\Delta)$

\section{DISCUSSION}

Both the model simulation and the meta-analysis of field data showed an increase in the specific growth rate of bacteria and predation pressure on bacteria with increasing productivity (10- and 100-fold, respectively). Hence, the predators (predator I in the model, flagellates and ciliates in the meta-analysis) were efficiently consuming the increase in BP that followed the increase in nutrient availability to eutrophic conditions. This resulted in a hump-shaped ratio of protozoan to bacterial biomass in the model simulation, similar to that observed in the meta-analysis. Thus, the food-web model predicted an increase in predation pressure, i.e. predation control of bacteria along aquatic productivity gradients with maximum predation control under mesoeutrophic conditions, which was verified by the metaanalysis of field data.

The food-web model simulation resulted in elevated biomass of the top predators (metazooplankton) and varying increases in the 4 lower trophic levels in response to increased productivity, partly similar to that predicted by the exploitation ecosystem hypothesis (Oksanen et al. 1981, Thingstad \& Sakshaug 1990). The results of our food-web model were not in agreement with the results presented by Gasol et al. (2002a), suggesting that flagellate predation controls bacteria in low productivity conditions. However, only flagellate predators were included in that study. Many protozoa utilize other food sources, and omnivory is quite common in the protozoan community, especially among ciliates (Fenchel 1987). Increasing ciliate biomass would influence both predation on flagellates and competition for their bacterial resource. It has been suggested that metazooplankton regulate the ciliate community in aquatic systems (Jürgens et al. 1999). In high-productivity and turbid environments, however, large metazooplankton especially are inefficient predators and ciliates are released from predation control (Porter \& McDonough 1984). Omnivorous ciliates and metazooplankton can be important predators of bacteria and the impact of these groups of predators on bacteria may increase in more productive aquatic systems (Jürgens 1994, Zingel et al. 2007). We only included small protozoa (e.g. heterotrophic nanoflagellates) as bacteriovores in our model. Despite this simplification we found that the predation pressure on bacteria was similar in the model simulations and in the meta-analysis. Thus, using our generalized model, we were able to simulate the predation pressure on bacteria in marine and freshwater systems and in oligotrophic through to eutrophic conditions. Even though our model did not include fish, the main response variable, i.e. predation pressure on bacteria, showed a similar response to increased productivity as that determined from the meta-analysis of field data. Since fish were a component of the studied natural aquatic systems, the results of our model may also be valid for ecosystems containing trophic levels higher than metazooplankton.

The model simulations resulted in lower rates of BP and predation compared to the meta-analysis (a factor of 100). This may partly have been caused by the relatively short residence time of the water in the model simulations (10 d). In natural aquatic systems the water residence time can often be months or years. In the 
model simulations the organisms did not have time to build up large biomasses before they were washed out of the system. When designing the food-web model, we chose to use published empirical parameters. Thus, parameters like bacterial C:N:P uptake rate, growth efficiency and photosynthetic efficiency were not optimized with parameter selection. Despite the shortcoming in mimicking productivity and biomass rates from the meta-analysis, we successfully modeled the main analysis variables of this study, i.e. predation pressure on bacteria and the ratio of protozoa to bacteria biomass. Furthermore, the bacteria-specific growth rates were successfully predicted along the productivity gradient. This shows that the model gave a realistic prediction of the dynamics within the pelagic food web, which was sufficient for this study. A majority of previous theoretical approaches to aquatic food-web dynamics and trophic interactions have been carried out using linear lumped-parameter models and a maximum of 3 trophic levels (Leibold 1989, Sanders et al. 1992, Abrams 1993, Thingstad \& Havskum 1999, Gasol et al. 2002a). Compared to previous studies on bacterial predation pressure (Sanders et al. 1992, Gasol et al. 2002a), we included omnivorous predators and covered a wider productivity range (oligotrophic to hypertrophic conditions) in our meta-analysis as well as in our simulations. The food-web model is based on physical constraints and published empirical parameters, while other models, e.g. lumped-parameter models, are based on differential equations and parameter selection (Leibold 1989, Sanders et al. 1992, Bohannan \& Lenski 2000). Interestingly, both the ecosystem model and the lumped-parameter models show an increasing importance of predation control of the basal trophic levels with increasing productivity of the system. Thus, the food-web structure seems to be more important than the choice of modeling approach when modeling population dynamics.

The meta-analysis of field data showed that the increase in protozoan predation over the productivity range $(685 \times)$ exceeded the increase in bacterial biomass $(44 \times$, Table 3$)$, indicating that predation pressure on bacteria was controlling the bacterial community in the eutrophic environments. The increase in predation pressure on bacteria was best explained by an increase in BP, but also by an increase in predator biomass. According to Wright \& Coffin (1984), a negative relationship between bacterial growth rate and bacterial abundance indicates that the bacteria are resource-limited. Thus, if bacterial growth rate and abundance are not related, the bacteria might be limited by predation (Wright \& Coffin 1984). We did not observe a decrease in the relationship between bacteria-specific growth rates and bacterial biomass over the nutrient range, suggesting that the bacterial communities were predator-limited.
In the meta-analysis, BP increased with increasing productivity of the aquatic system. This is in agreement with a previous study, where a positive correlation between BP and PP was observed in freshwater and marine ecosystems (Cole et al. 1988). In a lowproductivity aquatic system, flagellates have been shown to be mainly resource-limited or -controlled (Berglund et al. 2005). This indicates that the biomass resulting from an increase in bacterial productivity is consumed by the flagellates, and the bacterial biomass thus remains unchanged. This hypothesis has been tested in enclosure experiments, where BP increased markedly in response to addition of carbon and nitrogen while the bacterial biomass was unaltered (Kuuppo et al. 2003). The increased bacterial productivity resulted in an increased biomass of the highest trophic level in that study, i.e. the ciliate community. In our meta-analysis we also found an increase in the ratio of protozoan to bacterial biomass. Our results are in agreement with a field study of 55 lakes in northern Germany, where both flagellate and ciliate predators were included (Auer et al. 2004). The ratio of BP to protozoan predation showed no trend, either increasing or decreasing, over the nutrient range (data not shown). The ratio was on average $\sim 1$, indicating that protozoa constituted the main predators on bacteria. This is in accordance with a study in which BP and bacterial loss rate as a result of flagellate predation were shown to be balanced (Sanders et al. 1992). All data used in our meta-analysis were collected during the productive season. However, the occurrence of short-term predator-prey oscillations, as well as the seasonal succession in aquatic environments, might contribute to scatter in the data set. Other sources of scatter in the data might be the differences between the studies in the measurement of bacterial and protozoan response variables.

An increase in protozoan predation pressure is likely to trigger inducible defense mechanisms in the bacterial community (Jürgens \& Güde 1994). It has been shown previously that bacteria become more predation-resistant along aquatic productivity gradients (Thelaus et al. 2008). Bacteria may respond to high predation pressure by developing a wide diversity of predation resistance mechanisms, which either prevent their capture and ingestion by protozoa or hinder their degradation within the protozoa (Matz \& Kjelleberg 2005). This, in turn, would lead to a higher bacterial biomass at equilibrium (Vos et al. 2004). This might explain the increase in bacterial biomass observed over the productivity range in the meta-analysis. In our model simulations, which did not include the possibility of inducible defense mechanisms, the bacterial biomass increased from low to medium productivity levels, was nearly constant at intermediate productivity 
and then increased in the simulations of hypertrophic environments.

The presence of a high proportion of predation-resistant bacteria may lead to reduced regeneration of bacteria-bound nutrients and trophic transfer efficiencies in the food web (Jürgens \& Güde 1994). The observed increase in predation pressure on bacteria with increasing productivity might also apply to other basal resources in the food web, e.g. primary producers. One indication that this is the case is that blooms of toxic inedible phytoplankton are more common in eutrophic than in nutrient-poor waters (Paerl et al. 2001). The presence of inedible phytoplankton may in itself determine the influence of top-down versus bottom-up forces on a community (Bell 2002). The correlation between increasing predation pressure and the initiation of defense mechanisms by bacteria and phytoplankton indicates that there is a trade-off when expressing these mechanisms (Jürgens \& Güde 1994). Predation pressure must be strong enough to make it of evolutionary benefit for the organism to express energetically costly mechanisms to resist predation. Our study suggests that high-productivity aquatic environments constitute such situations.

In conclusion, we present a food-web model that is able to predict the predation pressure on bacteria over a productivity range, producing similar results to those derived from a meta-analysis of field data. In the model as well as in the meta-analysis of field data we found an increasing importance of protozoan predation in controlling the bacterial community with increasing productivity. Increasing predation pressure on bacteria along eutrophication gradients may be an important ecological mechanism that can lead to the evolution and occurrence of predation-resistant bacteria in highproductivity aquatic environments.

Acknowledgements. This study was supported by grants from the Centre for Environmental Research in Umeå (CMF no. 0322248), Umeå Marine Sciences Centre, the Swedish Ministry of Defence (no. A4854) and the Swedish Research Council (no. 60276201). We thank Dr. N. Blackburn for model programming and Prof. G. Englund for reviewing drafts of the manuscript.

\section{LITERATURE CITED}

Abrams PA (1993) Effect of increased productivity on the abundances of trophic levels. Am Nat 141:351-371

Andersson A, Haecky P, Hagström Å (1994) Effect of temperature and light on the growth of micro- nano- and picoplankton: impact on algal succession. Mar Biol 120: 511-520

- Auer B, Elzer U, Arndt H (2004) Comparison of pelagic food webs in lakes along a trophic gradient and with seasonal aspects: influence of resource and predation. J Plankton Res 26:697-709
Barcina I, Ayo B, Unanue M, Egea L, Iriberri J (1992) Comparison of rates of flagellate bacterivory and bacterial production in a marine coastal system. Appl Environ Microbiol $58: 3850-3856$

Bell T (2002) The ecological consequences of unpalatable prey: phytoplankton response to nutrient and predator additions. Oikos 99:59-68

Berglund J, Samuelsson K, Kull T, Muren U, Andersson A (2005) Relative strength of resource and predation limitation of heterotrophic nanoflagellates in a low-productive sea area. J Plankton Res 27:923-935

- Bettarel Y, Amblard C, Sime-Ngando T, Carrias JF, Sargos D, Garabetian F, Lavandier P (2003) Viral lysis, flagellate grazing potential, and bacterial production in lake Pavin. Microb Ecol 45:119-127

> Bettarel Y, Sime-Ngando T, Amblard C, Dolan J (2004) Viral activity in two contrasting lake ecosystems. Appl Environ Microbiol 70:2941-2951

Blackburn N, Azam F, Hagström ^̊ (1997) Spatially explicit simulations of a microbial food web. Limnol Oceanogr 42: $613-622$

Bohannan BJM, Lenski RE (2000) The relative importance of competition and predation varies with productivity in a model community. Am Nat 156:329-340

Christaki U, Giannakourou A, Van Wambeke F, Gregori G (2001) Nanoflagellate predation on auto- and heterotrophic picoplankton in the oligotrophic Mediterranean sea. J Plankton Res 23:1297-1310

> Cole JJ, Findlay S, Pace ML (1988) Bacterial production in fresh and saltwater ecosystems: a cross-system overview. Mar Ecol Prog Ser 43:1-10

Comte J, Jacquet S, Viboud S, Fontvieille D, Millery A, Paolini G, Domaizon I (2006) Microbial community structure and dynamics in the largest natural French lake (lake Bourget). Microb Ecol 52:72-89

Diehl S (2003) The evolution and maintenance of omnivory: dynamic constraints and the role of food quality. Ecology 84:2557-2567

Fenchel T (1987) Ecology of protozoa: the biology of freeliving phagotrophic protists. Brock/Springer series in contemporary bioscience. Science Tech, Madison, WI

Gasol JM, Pedros-Alio C, Vaque D (2002a) Regulation of bacterial assemblages in oligotrophic plankton systems: results from experimental and empirical approaches. Ant Leeuwenhoek 81:435-452

Gasol JM, Comerma M, Garcia JC, Armengol J, Casamayor EO, Kojecka P, Šimek K (2002b) A transplant experiment to identify the factors controlling bacterial abundance, activity, production, and community composition in a eutrophic canyon-shaped reservoir. Limnol Oceanogr 47: $62-77$

Hall SR, Leibold MA, Lytle DA, Smith VH (2006) Inedible producers in food webs: controls on stoichiometric food quality and composition of grazers. Am Nat 167:628-637

Hansen PJ, Björnsen PK, Hansen BW (1997) Zooplankton grazing and growth: scaling within the $2-2,000-\mu \mathrm{m}$ body size range. Limnol Oceanogr 42:687-704

Harris GD (1986) Phytoplankton ecology: structure, function and fluctuation. Chapman \& Hall, New York

Horñák K, Masin M, Jezbera J, Bettarel Y, Nedoma J, SimeNgando T, Šimek K (2005) Effects of decreased resource availability, protozoan grazing and viral impact on a structure of bacterioplankton assemblage in a canyon-shaped reservoir. FEMS Microbiol Ecol 52:315-327

Jardillier L, Boucher D, Personnic S, Jacquet S and others (2005) Relative importance of nutrients and mortality factors on prokaryotic community composition in two lakes of 
different trophic status: microcosm experiments. FEMS Microbiol Ecol 53:429-443

Jumars PA, Deming JW, Hill PS, Karp-Boss L, Yager PL, Dade WB (1993) Physical constraints on marine osmotrophy in an optimal foraging context. Aquat Microb Ecol 7:121-159

Jürgens K (1994) Impact of daphnia on planktonic microbial food webs - a review. Mar Microb Food Webs 8:295-324

Jürgens K, Güde H (1994) The potential importance of grazing-resistant bacteria in planktonic systems. Mar Ecol Prog Ser 112:169-188

Jürgens K, Skibbe O, Jeppesen E (1999) Impact of metazooplankton on the composition and population dynamics of planktonic ciliates in a shallow, hypertrophic lake. Aquat Microb Ecol 17:61-75

Kemp PF, Lee S, Laroche J (1993) Estimating the growth rate of slowly growing marine bacteria from RNA content. Appl Environ Microbiol 59:2594-2601

Klapper H (1991) Control of eutrophication in inland waters. Ellis Horwood series in water and wastewater technology. Ellis Horwood, Chichester

Kuuppo P, Samuelsson K, Lignell R, Seppälä J, Tamminen T, Andersson A (2003) Fate of increased production in latesummer plankton communities due to nutrient enrichment of the Baltic Proper. Aquat Microb Ecol 32:47-60

Kuuppo-Leinikki P (1990) Protozoan grazing on planktonic bacteria and its impact on bacterial population. Mar Ecol Prog Ser 63:227-238

Lee S, Fuhrman JA (1987) Relationships between biovolume and biomass of naturally derived marine bacterioplankton. Appl Environ Microbiol 53:1298-1303

Leibold MA (1989) Resource edibility and the effects of predators and productivity on the outcome of trophic interactions. Am Nat 134:922-949

Matz C, Kjelleberg S (2005) Off the hook - how bacteria survive protozoan grazing. Trends Microbiol 13:302-307

Myklestad SM (1995) Release of extracellular products by phytoplankton with special emphasis on polysaccharides. Sci Total Environ 165:155-164

- Oksanen L, Fretwell SD, Arruda J, Niemelä P (1981) Exploitation ecosystems in gradients of primary productivity. Am Nat 118:240-261

Paerl HW, Fulton RS III, Moisander PH, Dyble J (2001) Harmful freshwater algal blooms, with an emphasis on cyanobacteria. ScientificWorldJournal 1:76-113

Pelegri SP, Dolan J, Rassoulzadegan F (1999) Use of high temperature catalytic oxidation (HTCO) to measure carbon content of microorganisms. Aquat Microb Ecol 16:273-280

Porter KG, McDonough R (1984) The energetic cost of response to blue-green algal filaments by cladocerans. Limnol Oceanogr 29:365-369

Rousseau V, Becquevort S, Parent JY, Gasparini S, Daro MH, Tackx M, Lancelot C (2000) Trophic efficiency of the planktonic food web in a coastal ecosystem dominated by Phaeocystis colonies. J Sea Res 43:357-372

Sakshaug E, Slagstad D, Holmhansen O (1991a) Factors controlling the development of phytoplankton blooms in the Antarctic Ocean - a mathematical-model. Mar Chem 35: 259-271

Sakshaug E, Johnsen G, Andresen K, Vernet M (1991b) Modeling of light-dependent algal photosynthesis and growth: experiments with the Barents Sea diatoms Thalassiosira nordenskioldii and Chaetoceros furcellatus. Deep-Sea Res A 38:415-430

Sanders RW, Caron DA, Berninger UG (1992) Relationships between bacteria and heterotrophic nanoplankton in marine and fresh waters: an inter-ecosystem comparison. Mar Ecol Prog Ser 86:1-14

Šimek K, Armengol J, Comerma M, Garcia JC, Kojecka P, Nedoma J, Hejzlar J (2001a) Changes in the epilimnetic bacterial community composition, production, and protistinduced mortality along the longitudinal axis of a highly eutrophic reservoir. Microb Ecol 42:359-371

Šimek K, Pernthaler J, Weinbauer MG, Hornak K and others (2001b) Changes in bacterial community composition and dynamics and viral mortality rates associated with enhanced flagellate grazing in a mesoeutrophic reservoir. Appl Environ Microbiol 67:2723-2733

Šimek K, Hornak K, Masin M, Christaki U, Nedoma J, Weinbauer MG, Dolan JR (2003) Comparing the effects of resource enrichment and grazing on a bacterioplankton community of a meso-eutrophic reservoir. Aquat Microb Ecol 31:123-135

Solic M, Krstulovic N (1994) Role of predation in controlling bacterial and heterotrophic nanoflagellate standing stocks in the coastal Adriatic Sea: seasonal patterns. Mar Ecol Prog Ser 114:219-235

Sommaruga R (1995) Microbial and classical food webs: a visit to a hypertrophic lake. FEMS Microbiol Ecol 17:257-270

Sommaruga R, Psenner R (1995) Trophic interactions within the microbial food-web in Piburger-See (Austria). Arch Hydrobiol 132:257-278

Straile D (1997) Gross growth efficiencies of protozoan and metazoan zooplankton and their dependence on food concentration, predator-prey weight ratio, and taxonomic group. Limnol Oceanogr 42:1375-1385

Strom SL, Benner R, Ziegler S, Dagg MJ (1997) Planktonic grazers are a potentially important source of marine dissolved organic carbon. Limnol Oceanogr 42:1364-1374

Thelaus J, Forsman M, Andersson A (2008) Role of productivity and protozoan abundance for the occurrence of predation-resistant bacteria in aquatic systems. Microb Ecol 56: $18-28$

Thingstad TF, Havskum H (1999) Bacteria-protist interactions and organic matter degradation under P-limited conditions: analysis of an enclosure experiment using a simple model. Limnol Oceanogr 44:62-79

Thingstad TF, Sakshaug E (1990) Control of phytoplankton growth in nutrient recycling ecosystems. Theory and terminology. Mar Ecol Prog Ser 63:261-272

Vos M, Verschoor AM, Kooi BW, Wackers FL, DeAngelis DL, Mooij WM (2004) Inducible defenses and trophic structure. Ecology 85:2783-2794

> Wieltschnig C, Wihlidal P, Ulbricht T, Kirschner AKT, Velimirov B (1999) Low control of bacterial production by heterotrophic nanoflagellates in a eutrophic backwater environment. Aquat Microb Ecol 17:77-89

> Wieltschnig C, Fischer UR, Kirschner AKT, Velimirov B (2003) Benthic bacterial production and protozoan predation in a silty freshwater environment. Microb Ecol 46:62-72

Wienke SM, Cloern JE (1987) The phytoplankton component of seston in San Francisco Bay. Neth J Sea Res 21:25-33

> Wright RT, Coffin RB (1984) Measuring microzooplankton grazing on planktonic marine bacteria by its impact on bacterial production. Microb Ecol 10:137-149

Zingel P, Agasild H, Noges T, Kisand V (2007) Ciliates are the dominant grazers on pico- and nanoplankton in a shallow, naturally highly eutrophic lake. Microb Ecol 53:134-142

> Zweifel UL, Norrman B, Hagström Å (1993) Consumption of dissolved organic carbon by marine bacteria and demand for inorganic nutrients. Mar Ecol Prog Ser 101:23-32 